\title{
Understanding (un)certainty in human geographic quantitative spatial analysis - commentary to Tulumello
}

\section{OSSI KOTAVAARA}

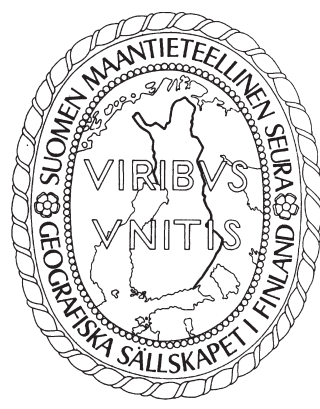

Kotavaara, O. (2019) Understanding (un)certainty in human geographic quantitative spatial analysis - commentary to Tulumello. Fennia 197(1) 160-162. https://doi.org/10.11143/fennia.80216

This commentary reflects uncertainty in human geographic quantitative spatial analysis within the context of Simone Tulumello's essay (in this issue). Epistemologically, positivism, logical empiricism and behaviourism must be understood as historical stages in the evolution of quantitative human geography, even though the analytical legacy is clear. A more recognisable quantitative methodological framework, related to postmillennial human geographic studies, seeks sufficient evidence, which supports or refutes a particular line of thought. In general, the consideration of uncertainty and error is deeply tied to the methodological knowledge in quantitative analysis. Regardless of methodology or discipline, however, the risks of reporting over-certainty or clear misconduct are essential ethical questions. Uncertainty is linked also to the limits of conceptualisation and information catchment, but robust information revealing otherwise-hidden patterns is often highly valuable.

Keywords: human geography, quantitative, uncertainty, spatial analysis, statistical modelling

Ossi Kotavaara, Geography research unit, University of Oulu, P.O. Box 3000, Fl-90014, Oulu, Finland. E-mail: ossi.kotavaara@oulu.fi

\section{Fragile, valuable and functional scientific constructions}

Tulumello's (2019) essay opens with an intriguing and playfully provoking debate concerning certainty, uncertainty and also maybe something that could be defined as 'pseudo certainty' in human geographic quantitative spatial analysis. In this spirit, I dare to state that positivism, logical empiricism, and behaviourism should be understood as historical strata buried deep under the actual foundations of present human geographic quantitative spatial analysis, instead of understanding them as vigorous paradigms in this field (Sheppard 2001). As the heritage of the quantitative revolution, however, substantial selection of useful analyses still has a significant role in building information, knowledge and society in the postmodern era. In general, quantitative human geographic research seeks large and complex patterns, and the methodology includes built-in error sources. This methodology, however, can produce new and evident information and, potentially be used to develop society. Again, qualitative human geography searches for something special, particular and, sometimes, unique that has the potential to be used to develop society. It is indeed worthy of attention that occasional studies, regardless of discipline and methodology, portray the research findings with more solid bases than they evidentially have. Thus, Tulumello's $(2019,127)$ conclusion that, "But, after all, it is important to acknowledge the scientific construction for its fragility, not solidity; for its continuous need of 
maintenance, refurbishing and restructuring. For, precarious as it is, it is the only shelter we have," leads to openness and reflectivity in constructing any type of information, knowledge or theory.

With this understanding, the reported collisions between qualitative and quantitative frameworks are actually the consequences of poor-quality teaching of analytics or narrow-minded thinking of scientists, not of the very debate with the present state-of-the-art or mainstream quantitative human geography. Indeed, the actual positivistic paradigm from the $19^{\text {th }}$ century and logical empiricism from the early $20^{\text {th }}$ century were strong and legitimate in the history of human geographic research. In studies carried out during or after the 'quantitative revolution' in the 1950s, a positivistic framework can accurately be included, but the idea of homo economicus was, to the best of my knowledge, largely rejected during the 1970s (Johnston \& Sidaway 2016). The quantitative methodological framework related to human geographic studies that is reported and discussed in journal articles and conferences follow closely the logic of Fotheringham, Brunsdon and Charlton $(2000,5)$ :

In (quantitative) human geography, where the subject matter is typically clouded by human idiosyncrasies, measurement problems and uncertainty, the search is not generally for hard evidence that global "laws" of human behaviour exist. Rather, the emphasis of quantitative analysis in human geography is to accrue sufficient evidence which makes the adoption of a particular line of thought compelling.

I carefully suggest, therefore, that the positivistic paradigm could be applied mainly to clarify the historical paradigm and not to define the context of post-millennial quantitative human geography.

\section{Some thoughts related to the uncertainty, dependence, causality and reality}

Quantitative analytical human geographic research has an extensive analytical framework relying on spatial and statistical methodologies. Condensing even the key epistemological discussions about some quantitative approaches would need significant efforts (e.g. Töttö 2000). In general, measuring uncertainty and level of error are deeply tied to the methodological knowledge in quantitative analysis. Even in the most basic levels of teaching, statistical dependence and causality are conceptually and analytically distinguished from each other. There are still researchers reporting over-certainty in findings or even producing misleading information, either negligently or purposely (Fanelli 2009). High-quality refereeing processes and ethical standards are needed, regardless of methodology or discipline, but also reporting inconsistencies and uncertainties openly should be supported more widely in the academic community and publishing process.

To discuss concisely uncertainty in modelling within human geography, I contradictory adopt the arrangement of Levins (1966) from the field of ecology (i.e. a field of hard natural science also considering spatial components) that out of generality, reality and precision, only two out of three desirable model properties can be improved simultaneously. Guisan and Zimmermann (2000) have built a representation of this trichotomy of models. The first group of models focuses on generality and precision, and they are designed to predict accurate responses within a limited or simplified reality. These models are applied, for example, in exploring and predicting population trends, health risks or land-use changes. The second group of models is designed to be realistic and general. These mechanistic or process models are based on real cause-and-effect relationships, and they may be considered as universally valid by the functional relationships. A model of this group is not judged primarily on predicted precision, but rather on the theoretical correctness of the predicted response. Similar to studies related to traffic safety (e.g. effects of using seatbelt, risk of drunk driving or benefits of replacing pedestrian crossing with underpass), it is possible to build highly valid models approaching causality with probabilities. The third group of models sacrifices generality for precision and reality. These empirical models are not expected to describe realistic causality, nor do they inform about supposed functions and mechanisms; instead, these models' main purpose is to condense empirical facts. For instance, a large questionnaire about housing preferences and residential satisfaction, connections between different types of responses may be explored deeply or condensed in understandable form; generalising the results to other areas, however, would be irrelevant.

In quantitative human geographic literature, significant efforts are paid to the applicability of methods. Put simply, sample size and spatial and statistical distributions limit available methods. To 
mention some classically recognised and common challenges, omitted-variable bias refers to a model where one or more relevant variables are not included, and their effects are attributed fallaciously to the other, included variables. Ecological fallacy refers to misleading deduction where conclusions considering individuals are based on observations related to a group. Again, the modifiable areal unit problem can significantly transform observations when small-scale measures are aggregated to largescale units or different spatial divisions.

Uncertainty is linked also to the limits of conceptualisation and information catchment. Couclelis (1982) derives well the need for simplification and uses the example of increasing complexity in building a spatial model for urban functions. Construction of the entity begins with Euclidean geometry, coordinate system and spatial information; it continues with measurable values, their institutional and social determinants, and it ends with person specific subjective valuations changing by time and context. Thus, the steps towards more realistic models from the simplest formal descriptions of information will, at some point, turn to numerous observer-dependent perceptions changing in time if a certain level of abstraction is not allowed. The balance between real and simple, therefore, may be best set at a level where enough robust information revealing otherwise-hidden patterns may be condensed to understandable and measurable form. Again, even though the methodology and analyses themselves are objective, this framework should encourage us to emphasise more that questions asked in research will be somewhat subjective.

\section{References}

Couclelis, H. (1982) Philosophy in the construction of geographic. In Gould, P. \& Olsson, G. (eds.) A Search for Common Ground, 105-138. Pion Limited, London.

Fanelli, D. (2009) How many scientists fabricate and falsify research? A systematic review and metaanalysis of survey data. PloS one 4(5) e5738. https://doi.org/10.1371/journal.pone.0005738

Fotheringham, A. S., Brunsdon, C. \& Charlton, M. (2000) Quantitative Geography: Perspectives on Spatial Data Analysis. SAGE publications, London.

Guisan, A. \& Zimmermann, N. E. (2000) Predictive habitat distribution models in ecology. Ecological Modelling 135(2-3) 147-186. https://doi.org/10.1016/S0304-3800(00)00354-9

Johnston R. \& Sidaway, J. (2016) Geography and Geographers: Anglo-American Human Geography Since 1945. $7^{\text {th }}$ ed. Routledge, London. https://doi.org/10.4324/9780203523056

Levins, R. (1966) The strategy of model building in population biology. American scientist 54(4) 421-431.

Sheppard, E. (2001) Quantitative geography: representations, practices, and possibilities. Environment and Planning D: Society and space 19(5) 535-554. https://doi.org/10.1068/d307

Tulumello, S. (2019) Generalization, epistemology and concrete: what can social sciences learn from the common sense of engineers. Fennia 197(1) 121-131. https://doi.org/10.11143/fennia.77626

Töttö, P. (2000) Pirullisen positivismin paluu. Laadullisen ja määrällisen tarkastelua. Vastapaino, Tampere. 